\title{
Hepatocellular Carcinoma by BCLC Stage
}

National Cancer Institute

\section{Source}

National Cancer Institute. Hepatocellular Carcinoma by BCLC Stage. NCI Thesaurus.

Code C115132.

A staging classification system for hepatocellular carcinoma that uses variables related to tumor stage, liver functional status, physical status, and cancer-related symptoms, and links the stages with a treatment algorithm. (HPB (Oxford) 2005; 7(1):35-41) 